\title{
SNAP-25 genotype influences NAA/Cho in left hippocampus
}

\author{
Harald Scherk · Martin Backens · Peter Zill · Thomas Schneider-Axmann • \\ Thomas Wobrock · Juliana Usher · Wolfgang Reith · Peter Falkai · \\ Hans-Jürgen Möller · Brigitta Bondy · Oliver Gruber
}

Received: 28 January 2008/ Accepted: 26 July 2008/Published online: 23 August 2008

(C) The Author(s) 2008. This article is published with open access at Springerlink.com

\begin{abstract}
The SNAP-25 gene is an integral part of the vesicle docking and fusion machinery that controls neurotransmitter release. Several post mortem studies revealed a reduction of SNAP-25 protein in the hippocampus of patients with schizophrenia and bipolar disorder (BD). Thirty-eight patients with schizophrenia, BD or obsessivecompulsive disorder and 17 healthy controls participated in the study. Proton magnetic resonance spectroscopy in left hippocampus was performed in each individual. Three single nucleotide polymorphisms (SNP) of the SNAP-25 gene were genotyped. Individuals with the homozygous CC genotype of the DdeI SNP presented a significantly higher ratio of $N$-acetyl-aspartate (NAA)/choline-containing compounds (Cho) in the left hippocampus compared to the group of individuals with the homozygous TT genotype. The SNAP-25 genotype may modulate synaptic plasticity and neurogenesis in the left hippocampus, and altered NAA/Cho ratio may be an indicator for this genetic modulation of neuronal function in the hippocampus.
\end{abstract}

H. Scherk $(\bowtie)$ - T. Schneider-Axmann - T. Wobrock ·

J. Usher · P. Falkai · O. Gruber

Department of Psychiatry and Psychotherapy,

Georg-August-University Goettingen,

von-Siebold-Str. 5, 37075 Göttingen, Germany

e-mail: hscherk@uni-goettingen.de

M. Backens · W. Reith

Department of Neuroradiology,

Saarland University Hospital, Homburg, Germany

P. Zill · H.-J. Möller · B. Bondy

Department of Psychiatry and Psychotherapy,

LM University of Munich, Munich, Germany
Keywords Proton magnetic resonance spectroscopy · SNAP-25 $\cdot N$-acetyl-aspartate $\cdot$ Choline $\cdot$ Hippocampus

\section{Introduction}

In major psychiatric disorders like schizophrenia, bipolar affective disorder and obsessive-compulsive disorder (OCD) a disturbed neurotransmitter function has been postulated to play a key role in the aetiology of these diseases. The neurotransmitter release from the vesicles of the presynaptic neuron into the synaptic cleft is controlled by a protein complex. An integral part of this vesicle docking and fusion machinery is the SNAP-25 gene product (Oyler et al. 1989). The transient localization in axons within the developing brain indicates that SNAP-25 might be required for plasticity of neuro- and synaptogenesis (Osen-Sand et al. 1993; Sollner et al. 1993). The SNAP-25 gene is highly expressed in the hippocampus (Geddes et al. 1999). It might therefore influence the neuronal density and connectivity of the hippocampus. The hippocampal formation is involved in the neuronal pathology of major psychiatric disorders like schizophrenia (Harrison 2004), bipolar affective disorder (Phillips et al. 2003), and OCD (Kwon et al. 2003). Several post mortem studies revealed a reduction of SNAP-25 protein in the hippocampus of patients with schizophrenia (Young et al. 1998; Thompson et al. 2003) and bipolar disorder (BD; Fatemi et al. 2001). These results underline the importance of SNAP-25 protein in major psychiatric disorders. Furthermore, animal studies showed that the hippocampal SNAP-25 protein is involved in memory consolidation and long-term memory formation in rats (Hou et al. 2004, 2006). In humans it has been shown recently that the SNAP-25 gene is associated with the cognitive ability of healthy individuals (Gosso et al. 2006). 
Proton magnetic resonance spectroscopy ( ${ }^{1} \mathrm{H}-\mathrm{MRS}$ ) allows in vivo determination of several brain metabolites such as $N$-acetyl-aspartate (NAA), choline-containing compounds (Cho), creatine + phosphocreatine $(\mathrm{Cr})$ and inositol + myo-inositol (Ins). NAA is a generally accepted marker for neuronal density and function, even though its exact role in brain metabolism is still unclear. Cho primarily reflects cell membrane phospholipids and cell membrane turnover, $\mathrm{Cr}$ represents cell energy metabolism and Ins participates in phospholipid metabolism and signal transduction (Burtscher and Holtas 2001). Because absolute quantification of these compounds is difficult to achieve, most studies focus on specific ratios between the markers of interest and the markers which are most expected. Generally the ratios NAA/Cr, NAA/Cho, $\mathrm{Cho/Cr}$ and $\mathrm{Ins} / \mathrm{Cr}$ are chosen. They allow the indirect estimation of the underlying metabolite concentrations. For example, increased ratios of $\mathrm{NAA} / \mathrm{Cr}$ and NAA/Cho in combination with unchanged $\mathrm{Cho} / \mathrm{Cr}$ ratio suggest an increased absolute NAA concentration. ${ }^{1} \mathrm{H}$-MRS studies in patients with schizophrenia observed decreased NAA concentrations in the hippocampus (Steen et al. 2005). In patients with BD NAA seems to be reduced in manic, depressive and euthymic mood states (Yildiz-Yesiloglu and Ankerst 2006).

To our knowledge there are no studies that investigated the influence of SNAP-25 genotype on metabolite ratios in hippocampus in major psychiatric disorders. Three different single nucleotide polymorphisms (SNP; MnlI, TaiI and $D d e I$ in the $3^{\prime}$-untranslated region) were chosen for the present analysis as they have been associated with cognitive dysfunction, as well as antipsychotic induced weight gain in schizophrenic patients and attention deficit hyperactivity disorders (Spellmann et al. 2008; Musil et al. 2008; Kim et al. 2007; Müller et al. 2005; Mill et al. 2004; Brophy et al. 2002; Kustanovich et al. 2003; Barr et al. 2000).

The aim of the present study was to determine whether three different SNAP-25 SNPs alter, irrespective of clinical diagnosis, the metabolic ratios NAA/Cho, NAA/Cr, Cho/Cr and $\mathrm{Ins} / \mathrm{Cr}$ in the hippocampus. In order to address this issue, we acquired ${ }^{1} \mathrm{H}-\mathrm{MRS}$ data from the left hippocampus in healthy individuals and psychiatric patients suffering from schizophrenia, BD or OCD.

\section{Methods and materials}

\section{Subjects}

Nine patients suffering their first episode of schizophrenia (SZ), nineteen euthymic patients with bipolar I disorder, ten patients with OCD, and seventeen healthy control (HC) subjects participated in the study. Written informed consent was obtained from all subjects and the study was approved by the local ethical committee. Subjects were recruited from the outpatient unit of the Department of Psychiatry and Psychotherapy of the Saarland University Hospital. The diagnoses of schizophrenia, BD and OCD were confirmed by using the German version of the Structural Clinical Interview for DSM-IV (Wittchen et al. 1997). All patients received stable medication at the time of the study. Eight patients with SZ received antipsychotics, 18 patients with BD took one or more mood-stabilizer (six lithium, five valproate, nine lamotrigine, three carbamazepine), nine received an antipsychotic and seven an antidepressant drug, six patients with OCD were treated with an antidepressant drug.

\section{${ }^{1} \mathrm{H}-\mathrm{MRS}$}

Single-volume ${ }^{1} \mathrm{H}$-MRS was performed on a 1.5 -Tesla Siemens Magnetom Sonata (Siemens, Erlangen) using a spin-echo sequence with water-suppression and 128 scan averages $(\mathrm{TE}=30, \mathrm{TR}=1,500)$. The region of interest was determined in the left hippocampus according to an exactly predefined and standardized algorithm with multiple rechecking procedures in a T2-gradient echo image (TrueFISP) with 24 slices each in three orthogonal orientations. The positions of the voxels were visually inspected and adjusted based on identifiable anatomical landmarks in reference to standard brain atlases (Talairach and Tournoux 1998; Duvernoy 1999). The voxel size was $10 \times \times 35 \times 10 \mathrm{~mm}^{3}$.

\section{Genotyping}

Genomic DNA was isolated from whole blood according to standard procedures. Three restriction fragment length polymorphisms (RFLP) in the SNAP-25 were genotyped with the enzymes MnlI, DdeI and TaiI (MBI Fermentas, Amherst, NY, USA). These SNPs were chosen according to previous reports relating significant associations between these three polymorphisms and cognitive dysfunction, as well as antipsychotic induced weight gain in schizophrenic patients and attention deficit hyperactivity disorders (Spellmann et al. 2008; Musil et al. 2008; Kim et al. 2007; Müller et al. 2005; Mill et al. 2004; Brophy et al. 2002; Kustanovich et al. 2003; Barr et al. 2000).

The MnlI- (T/G substitution) and the DdeI- (T/C substitution) SNPs are closely opposed (four base pairs apart) and can be visualized using the same PCR amplicon. The Tai I RFLP is a T/C substitution 658 and 654 bp downstream of the MnlI and DdeI polymorphisms. The corresponding SNP ID numbers were as follows: rs3746544 (MnlI); rs1051312 (DdeI), rs8636 (TaiI) from http://www.ncbi.nlm.nih.gov/SNP/.

For genotyping the MnlI (T to G substitution) and DdeI (T to $\mathrm{C}$ substitution) SNPs the same protocol was used as 
described previously by Barr and collaborators (Barr et al. 2000). For PCR amplification of the TaiI SNP the same protocols was used as described by Wong et al. (2003). The calculation of the pairwise linkage disequilibrium (LD) between the SNPs was done by using the program HAPLOVIEW (http://www.broad.mit.edu/mpg/haploview/ index.php) (Barrett et al. 2005).

\section{Statistics}

For statistical analyses SPSS for Windows 14 was used. All tests were two-tailed. Level of significance was $P=0.05$. Dependent variables were metabolic ratios (NAA/Cho, $\mathrm{NAA} / \mathrm{Cr}, \mathrm{Cho} / \mathrm{Cr}$ and $\mathrm{Ins} / \mathrm{Cr}$ ) in the left hippocampus. Three different analyses were conducted with the SNAP-25 polymorphisms DdeI, TaiI or MnlI as independent factors. One-way analysis of variance (ANOVA) was calculated to analyse if there were significant age or education differences between the genotypes. Chi-square test on independence was used to analyse if distribution of diagnosis, gender and hand preference was different between the groups.

For the four hippocampal metabolic ratios a multivariate ANOVA was performed separately for DdeI, TaiI and MnlI. If there was a significant effect in a three-group comparison, a subgroup analysis between two of the three genotypes each was performed applying a Bonferroni adjustment for three comparisons. A multivariate ANOVA with the metabolic ratios as dependent variables and the independent factor diagnosis was additionally conducted for all subjects with the homozygous TT genotype.

\section{Results}

For the objective of this study the individuals were grouped according to the different SNP genotypes. The analysis of the LD showed a strong LD between the TaiI and MnlI polymorphisms. The DdeI polymorphism was not in LD to the two other polymorphisms.

No associations between MnlI or TaiI genotypes and the metabolic ratios were found. Regarding the DdeI genotype 31 individuals (6 SZ, $11 \mathrm{BD}, 6 \mathrm{OCD}, 8 \mathrm{HC})$ had the homozygous TT genotype, 19 individuals ( $3 \mathrm{SZ}, 5 \mathrm{BD}, 4$ OCD, $7 \mathrm{HC}$ ) had the heterozygous TC genotype, and 5 individuals ( $0 \mathrm{SZ}, 3 \mathrm{BD}, 0 \mathrm{OCD}, 2 \mathrm{HC})$ had the homozygous CC genotype. The distribution of different genotypes is in accord with their occurrence in the general population. The different groups of individuals with distinct genotypes exhibited no significant differences regarding mean age, gender, handedness or education (Table 1).

Multivariate analyses with the independent factor genotype revealed a significant influence of SNAP-25 DdeI genotype on metabolite ratio NAA/Cho in the left hippocampus $(F=3.91 ; d f=2,52 ; P=0.026)$ (Table 2$)$. Subsequent subgroup analysis showed that this ratio was significantly higher in individuals with homozygous CC compared to homozygous TT genotype $[+33 \%$, $P=0.012$ (Bonferroni adjusted)], while the mean value of the heterozygous genotype TC ranged-however not significantly-between the mean values of the homozygous genotypes (Fig. 1). No significant associations between SNAP-25 DdeI genotype and the other metabolic ratios in hippocampus were observed. However, the analysis revealed a trend for the $\mathrm{Cho} / \mathrm{Cr}$ ratio, as numerically it was decreased in carriers of the CC compared to the TT genotype $(-15.4 \%, F=2.64 ; d f=2,52, P=0.081)$. A further multivariate analysis of all subjects with the homozygous TT genotype with the independent factor diagnosis revealed no significant different mean values of the NAA/Cho ratio between the four diagnostic groups (HC 2.26, SZ 2.40, BD 2.27, OCD 2.21, $F=0.15$, $P=0.93$ ).

Table 1 Demographic data of subjects

\begin{tabular}{|c|c|c|c|c|c|c|}
\hline & \multicolumn{3}{|l|}{ Genotype } & \multirow[t]{2}{*}{$d f$} & \multirow[t]{2}{*}{$F / \chi^{2}$} & \multirow[t]{2}{*}{$P$-value ${ }^{\mathrm{a}}$} \\
\hline & $\mathrm{TT}$ & $\mathrm{TC}$ & $\mathrm{CC}$ & & & \\
\hline Schizophrenia $(n)$ & 6 & 3 & 0 & & & \\
\hline $\mathrm{BD}(n)$ & 11 & 5 & 3 & & & \\
\hline $\operatorname{OCD}(n)$ & 6 & 4 & 0 & & & \\
\hline Healthy controls $(n)$ & 8 & 7 & 2 & & & \\
\hline All individuals $(n)$ & 31 & 19 & 5 & & & \\
\hline Age (years; mean $\pm \mathrm{SD}$ ) & $37.9 \pm 12.4$ & $36.1 \pm 15.1$ & $42.8 \pm 13.5$ & 1,34 & 0.68 & 0.42 \\
\hline Gender (male/female) & $15 / 16$ & $6 / 13$ & $2 / 3$ & 1 & 0.12 & 0.73 \\
\hline Education (years; mean \pm SD) & $13.9 \pm 2.4$ & $13.8 \pm 3.2$ & $16.0 \pm 2.9$ & 1,33 & 3.08 & 0.089 \\
\hline Handedness (right/not-right) & $24 / 6$ & $16 / 2$ & $4 / 0$ & 1 & 0.97 & 0.32 \\
\hline
\end{tabular}

$B D$ bipolar disorder, $n$ number, $O C D$ obsessive-compulsive disorder, $S D$ standard deviation

${ }^{\text {a }}$ In the statistical analysis the group TC is excluded 


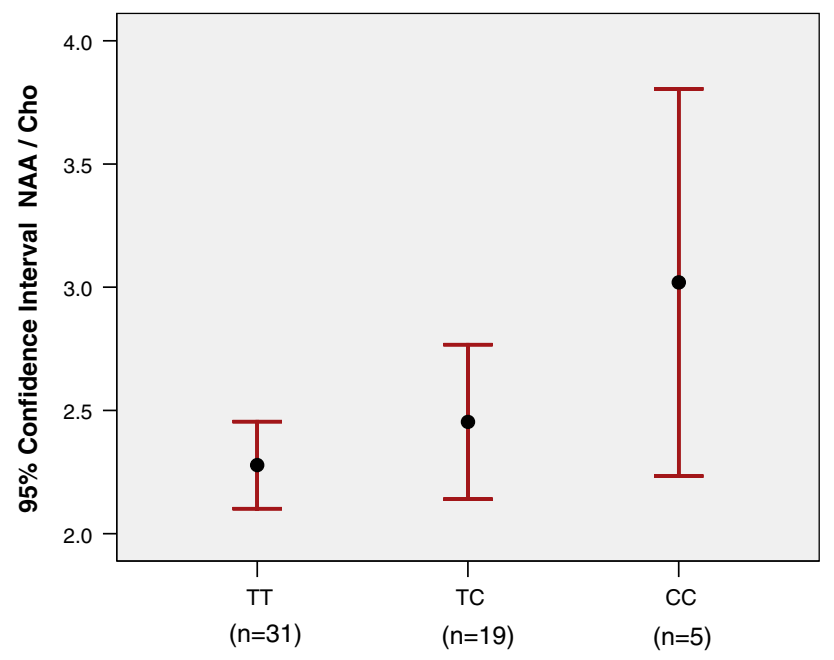

Fig. 1 Error bars plot of NAA/Cho ratio in left hippocampus. Individuals with SNAP-25 DdeI CC genotype exhibited significantly increased ratio of NAA/Cho $(P=0.012)$ compared to individuals with the TT genotype

\section{Discussion}

This study investigated the influence of three different SNAP-25 SNPs (MnlI, TaiI and DdeI in the 3 '-UTR) on the metabolic ratios NAA/Cho, NAA/Cr, Cho/Cr and $\mathrm{Ins} / \mathrm{Cr}$ in the left hippocampus in healthy individuals and psychiatric patients suffering from schizophrenia, BD or OCD. The analysis revealed that subjects with the homozygous $\mathrm{CC}$ genotype of the DdeI polymorphism presented a significantly higher NAA/Cho ratio than subjects with the homozygous TT genotype. Although there were only significant differences between the homozygous SNAP-25 DdeI CC and TT genotypes, the mean value of the NAA/ Cho ratio in the heterozygous TC group lay between the values of the homozygous groups. This result might indicate an allele effect on NAA/Cho ratio.

The finding of a significantly increased NAA/Cho ratio, an unchanged $\mathrm{NAA} / \mathrm{Cr}$ ratio and a non-significantly decreased $\mathrm{Cho} / \mathrm{Cr}$ ratio might indicate on the one hand an increased NAA concentration or on the other hand decreased Cho. As we were unable to assess the absolute concentration of NAA and Cho themselves, we will discuss both possible outcomes.

The first presumption is that the results of this study indicate enhanced NAA levels in the left hippocampus in carriers of the homozygous SNAP-25 DdeI CC genotype. Following this view we conclude that individuals with the CC genotype possess a higher neuronal density or function in the left hippocampus than individuals with the other genotypes as NAA is generally assumed to be a marker for neuronal density and function (Burtscher and Holtas 2001). The SNAP-25 genotype appears therefore to modulate the neuronal density and neuronal function in the left hippocampus. This assumption is in accord with prior findings of the involvement of SNAP-25 in neuroand synaptogenesis (Osen-Sand et al. 1993; Sollner et al. 1993). This suggests that the observed genetic effect might be related to a basic regulation mechanism of neuro- and synaptogenesis and, moreover, synaptic transmission in the hippocampus. This SNAP-25 modulated mechanism might influence the hippocampal function. It is possible, therefore, that the reported association of SNAP-25 genotype with memory consolidation (Hou et al. 2004) and long-term memory formation (Hou et al. 2006) in rats as well as cognitive ability in humans (Gosso et al. 2006) is caused by its influence on hippocampal function.

The second assumption is that the results of this study demonstrate reduced amounts of Cho in the left hippocampus in carriers of the homozygous SNAP-25 DdeI CC genotype. Choline measured via ${ }^{1} \mathrm{H}$-spectroscopy is believed to represent mostly phosphocholine and glycerophosphocholine and less than 5\% free choline and acetylcholine. The choline signal is therefore assumed to reflect cell membrane metabolism or turnover and synaptic plasticity (Sartorius et al. 2006). The presumed reduced choline amount in the present study might represent a reduced membrane turnover following reduced synaptic plasticity and neurogenesis in the left hippocampus. This conclusion is also in accord with the above mentioned involvement of SNAP-25 in neuro- and synaptogenesis (Osen-Sand et al. 1993; Sollner et al. 1993).

Table $2{ }^{1} \mathrm{H}$-MRS results in left hippocampus of individuals with SNAP-25 DdeI genotype

\begin{tabular}{|c|c|c|c|c|c|c|c|c|c|}
\hline & \multirow{2}{*}{$\begin{array}{l}\text { TT }(n=31) \\
\text { Mean } \pm \text { SD }\end{array}$} & \multirow{2}{*}{$\begin{array}{l}\text { TC }(n=19) \\
\text { Mean } \pm \text { SD }\end{array}$} & \multirow{2}{*}{$\begin{array}{l}\mathrm{CC}(n=5) \\
\text { Mean } \pm \mathrm{SD}\end{array}$} & \multicolumn{3}{|c|}{ MANOVA } & \multicolumn{3}{|c|}{ Subgroup analysis ${ }^{\mathrm{a}}$} \\
\hline & & & & $d f$ & $F$-value & $P$-value & $\begin{array}{l}\mathrm{CC} \text { vs. TT } \\
P \text {-value }\end{array}$ & $\begin{array}{l}\mathrm{CC} \text { vs. TC } \\
P \text {-value }\end{array}$ & $\begin{array}{l}\text { TC vs. TT } \\
P \text {-value }\end{array}$ \\
\hline NAA/Cho & $2.28 \pm 0.48$ & $2.46 \pm 0.65$ & $3.02 \pm 0.63$ & 2,52 & 3.91 & 0.026 & 0.012 & 0.15 & 0.85 \\
\hline NAA/Cr & $2.11 \pm 0.41$ & $2.01 \pm 0.42$ & $2.34 \pm 0.42$ & 2,52 & 0.72 & 0.49 & 0.78 & 0.77 & 1.00 \\
\hline $\mathrm{Cho} / \mathrm{Cr}$ & $0.94 \pm 0.16$ & $0.88 \pm 0.12$ & $0.80 \pm 0.18$ & 2,52 & 2.64 & 0.081 & 0.20 & 0.83 & 0.43 \\
\hline $\mathrm{Ins} / \mathrm{Cr}$ & $0.52 \pm 0.18$ & $0.46 \pm 0.14$ & $0.50 \pm 0.3$ & 2,52 & 0.73 & 0.49 & 1.00 & 1.00 & 0.70 \\
\hline
\end{tabular}

${ }^{a}$ In the subgroup analysis, Bonferroni adjusted $P$-values for three comparisons were used 
The two discussed possible results indicate contrarian conclusions. Higher NAA might represent increased whilst reduced choline might imply reduced synaptic plasticity and neurogenesis. In view of this antagonism a clear conclusion cannot be made. However, the results of this study indicate a significant influence of SNAP-25 genotype on neuro- and synaptogenesis.

The estimation of brain metabolites using ${ }^{1} \mathrm{H}$-MRS does not allow forthright conclusions on underlying molecular processes. Our interpretation must therefore be handled with care. Moreover, the possible effects of genes or polymorphisms on brain metabolites measured with ${ }^{1} \mathrm{H}$ MRS are mostly unknown. Two recent studies, however, reported effects of different genes on NAA in the human brain. One study observed a significant reduction of NAA/ $\mathrm{Cr}$ levels in the right dorsolateral prefrontal cortex in homozygous A-allele carriers of a SNP in the metabotropic glutamate receptor 3 (Marenco et al. 2006). Another study revealed higher ratios of NAA/Cho and NAA/Cr in the left putamen in individuals with the homozygous DAT1 10repeat genotype compared to carriers of 9-repeat allele (Scherk et al. 2007). These studies emphasize that genetic polymorphisms might influence metabolite ratios in some brain regions. The DdeI polymorphism resides in the $3^{\prime}$ untranslated region and does not affect the protein's amino acid sequence. However, it has been shown that untranslated regions of genes play an important role in the regulation of transcription efficiency, mRNA stability or mRNA sub-cellular localization (Grehan et al. 2001; Mignone et al. 2002).

The results of this study are limited by some major methodological restrictions. The small size of the SNAP-25 $D d e$ I CC genotype group with only five subjects impairs the statistical analysis. The presented results should therefore be treated with caution and classified as preliminary data until they can be confirmed in future studies. Minor methodological restrictions were that we did not obtain a differentiation between proportions of grey or white matter in the investigated volumes of interest. Therefore, we cannot definitely exclude that differences of grey and white matter proportions between different subjects might have influenced the metabolite concentrations, although the positioning of the volume of interest was visually inspected and adjusted based on identifiable anatomical landmarks in reference to standard brain atlases (Talairach and Tournoux 1998; Duvernoy 1999). Moreover, we only estimated relative metabolite concentrations and computed metabolite ratios such as NAA/Cr, NAA/ Cho, and the $\mathrm{Cho} / \mathrm{Cr}$ ratio instead of absolute metabolite concentrations. This is an approved method to estimate changes of metabolites. Nonetheless this method has some restrictions since some studies showed that the creatine level is not as stable as mentioned so far.
In this study haplotype analysis of the three SNPs was not applied due to several reasons: We found that the SNAP-25 TaiI and MnlI polymorphisms are in LD in our study samples. The DdeI polymorphism was not in LD to the two other polymorphisms, possibly suggesting a putative recombination hotspot between these SNP's. This finding was also formerly described by Spellmann et al. and Mueller et al. Therefore the SNPs are not within a haplotype block for a reasonable analysis. On the other hand the common computer programs for haplotype analysis perform only haplotype estimations with no clear assignment of a specific haplotype to a single person. Such an approach would require the parents of each individual to determine the exact inheritance.

Due to the explorative character of the study, we did not apply the Bonferroni correction for the number of tests. Moreover, it has to be mentioned that the Bonferroni procedure is a very conservative method and that it is not appropriate here as some of the SNPs are in LD and therefore not all the tests independent.

Interestingly, several reports find associations between the DdeI and MnlI polymorphism of the SNAP-25 gene with ADHD in different populations (Choi et al. 2007; Kustanovich et al. 2003; Mill et al. 2004). Moreover, imaging studies support growing evidence that the hippocampus and other limbic regions are involved in the patho-physiology of ADHD (Plessen et al. 2006; Volkow et al. 2007). So far ${ }^{1} \mathrm{H}-$ MRS studies of hippocampus in ADHD are missing (Perlov et al. 2008). Nevertheless, these data suggest an involvement of the SNAP-25 gene in different major psychiatric disorders and on hippocampus structure and function.

Taken together, these preliminary findings are consistent with the view that the SNAP-25 genotype may modulate synaptic plasticity and neurogenesis in the left hippocampus, and that an altered NAA/Cho ratio may be an indicator for this genetic modulation of neuronal function in the hippocampus. It seems to be worthwhile to investigate the relationship between SNAP-25 and metabolite ratios in further studies.

Acknowledgement This study was supported by a grant from the Saarland University Hospital, Germany to HS (HOMFOR A/2003/21).

Open Access This article is distributed under the terms of the Creative Commons Attribution Noncommercial License which permits any noncommercial use, distribution, and reproduction in any medium, provided the original author(s) and source are credited.

\section{References}

Barr CL, Feng Y, Wigg K, Bloom S, Roberts W, Malone $\mathrm{M}$ et al (2000) Identification of DNA variants in the SNAP-25 gene and linkage study of these polymorphisms and attention-deficit hyperactivity disorder. Mol Psychiatry 5:405-409 
Barrett JC, Fry B, Maller J, Daly MJ (2005) Haploview: analysis and visualization of LD and haplotype maps. Bioinformatics 21:263265

Brophy K, Hawi Z, Kirley A, Fitzgerald M, Gill M (2002) Synaptosomal-associated protein 25 (SNAP-25) and attention deficit hyperactivity disorder (ADHD): evidence of linkage and association in the Irish population. Mol Psychiatry 7(8):913-917

Burtscher IM, Holtas S (2001) Proton MR spectroscopy in clinical routine. J Magn Reson Imaging 13:560-567

Choi TK, Lee HS, Kim JW, Park TW, Song DH, Yook KW et al (2007) Support for the MnlI polymorphism of SNAP25; a Korean ADHD case-control study. Mol Psychiatry 12(3):224-226

Duvernoy HM (1999) The human brain. Surface, three-dimensional sectional anatomy and MRI: surface, three-dimensional sectional anatomy with MRI and blood supply. Springer, Vienna

Fatemi SH, Earle JA, Stary JM, Lee S, Sedgewick J (2001) Altered levels of the synaptosomal associated protein SNAP-25 in hippocampus of subjects with mood disorders and schizophrenia. Neuroreport 12:3257-3262

Geddes JW, Hess EJ, Hart RA, Kesslak JP, Cotman CW, Wilson MC (1999) Lesions of hippocampal circuitry define synaptosomalassociated protein-25 (SNAP-25) as a novel presynaptic marker. Neuroscience 38:515-525

Gosso MF, de Geus EJ, van Belzen MJ, Polderman TJ, Heutink P, Boomsma DI et al (2006) The SNAP-25 gene is associated with cognitive ability: evidence from a family-based study in two independent Dutch cohorts. Mol Psychiatry 11:878-886

Grehan S, Allan C, Tse E, Walker D, Taylor JM (2001) Expression of the apolipoprotein $\mathrm{E}$ gene in the skin is controlled by a unique downstream enhancer. J Invest Dermatol 116(1):77-84

Harrison PJ (2004) The hippocampus in schizophrenia: a review of the neuropathological evidence and its pathophysiological implications. Psychopharmacology (Berl) 174:151-162

Hou Q, Gao X, Zhang X, Kong L, Wang X, Bian W et al (2004) SNAP-25 in hippocampal CA1 region is involved in memory consolidation. Eur J Neurosci 20:1593-1603

Hou QL, Gao X, Lu Q, Zhang XH, Tu YY, Jin ML et al (2006) SNAP-25 in hippocampal CA3 region is required for long-term memory formation. Biochem Biophys Res Commun 347:955962

Kim JW, Biederman J, Arbeitman L, Fagerness J, Doyle AE, Petty C et al (2007) Investigation of variation in SNAP-25 and ADHD and relationship to co-morbid major depressive disorder. Am $\mathrm{J}$ Med Genet B Neuropsychiatr Genet 144B(6):781-790

Kustanovich V, Merriman B, McGough J, McCracken JT, Smalley SL, Nelson SF (2003) Biased paternal transmission of SNAP-25 risk alleles in attention-deficit hyperactivity disorder. Mol Psychiatry 8(3):309-315

Kwon JS, Shin YW, Kim CW, Kim YI, Youn T, Han MH et al (2003) Similarity and disparity of obsessive-compulsive disorder and schizophrenia in MR volumetric abnormalities of the hippocampus-amygdala complex. J Neurol Neurosurg Psychiatry 74:962964

Marenco S, Steele SU, Egan MF, Goldberg TE, Straub RE, Sharrief AZ et al (2006) Effect of metabotropic glutamate receptor 3 genotype on $\mathrm{N}$-acetyl aspartate measures in the dorsolateral prefrontal cortex. Am J Psychiatry 163(4):740-742

Mignone F, Gissi C, Liuni S, Pesole G (2002) Untranslated regions of mRNAs. Genome Biol 3(3)

Mill J, Richards S, Knight J, Curran S, Taylor E, Asherson P (2004) Haplotype analysis of SNAP-25 suggests a role in the aetiology of ADHD. Mol Psychiatry 9(8):801-810

Müller DJ, Klempan TA, De Luca V, Sicard T, Volavka J, Czobor P et al (2005) The SNAP-25 gene may be associated with clinical response and weight gain in antipsychotic treatment of schizophrenia. Neurosci Lett 379(2):81-89
Musil R, Spellmann I, Riedel M, Dehning S, Douhet A, Maino K et al (2008) SNAP-25 gene polymorphisms and weight gain in schizophrenic patients. J Psychiatr Res [Epub ahead of print]

Osen-Sand A, Catsicas M, Staple JK, Jones KA, Ayala G, Knowles J et al (1993) Inhibition of axonal growth by SNAP-25 antisense oligonucleotides in vitro and in vivo. Nature 364(6436):445-448

Oyler GA, Higgins GA, Hart RA, Battenberg E, Billingsley M, Bloom FE et al (1989) The identification of a novel synaptosomal-associated protein, SNAP-25, differentially expressed by neuronal subpopulations. J Cell Biol 109:3039-3052

Perlov E, Alexandra P, Swantje M, Tobias D, Simon M, Emanuel B et al (2008) Spectroscopic findings in attention-deficit/hyperactivity disorder: review and meta-analysis. World J Biol Psychiatry 1-11 [Epub ahead of print]

Phillips ML, Drevets WC, Rauch SL, Lane R (2003) Neurobiology of emotion perception II: implications for major psychiatric disorders. Biol Psychiatry 54:515-528

Plessen KJ, Bansal R, Zhu H, Whiteman R, Amat J, Quackenbush GA et al (2006) Hippocampus and amygdala morphology in attention-deficit/hyperactivity disorder. Arch Gen Psychiatry 63(7):795-807

Sartorius A, Schloss P, Vollmayr B et al (2006) Correlation between MR-spectroscopic rat hippocampal choline levels and phospholipase A2. World J Biol Psychiatry 7:246-250

Scherk H, Backens M, Schneider-Axmann T, Kraft S, Kemmer C, Usher J et al (2007) Dopamine transporter genotype influences $\mathrm{N}$-acetyl-aspartate in left putamen. World J Biol Psychiatry Oct 26:1-7 [Epub ahead of print]

Sollner T, Whiteheart SW, Brunner M, Erdjument-Bromage H, Geromanos S, Tempst P et al (1993) SNAP receptors implicated in vesicle targeting and fusion. Nature 362:318-324

Spellmann I, Müller N, Musil R, Zill P, Douhet A, Dehning S et al (2008) Associations of SNAP-25 polymorphisms with cognitive dysfunctions in Caucasian patients with schizophrenia during a brief trail of treatment with atypical antipsychotics. Eur Arch Psychiatry Clin Neurosci [Epub ahead of print]

Steen RG, Hamer RM, Lieberman JA (2005) Measurement of brain metabolites by $1 \mathrm{H}$ magnetic resonance spectroscopy in patients with schizophrenia: a systematic review and meta-analysis. Neuropsychopharmacology 30:1949-1962

Talairach J, Tournoux P (1998) Coplanar stereotaxic atlas of the human brain. Thieme Medical Publishers, New York

Thompson PM, Egbufoama S, Vawter MP (2003) SNAP-25 reduction in the hippocampus of patients with schizophrenia. Prog Neuropsychopharmacol Biol Psychiatry 27:411-417

Volkow ND, Wang GJ, Newcorn J, Telang F, Solanto MV, Fowler JS et al (2007) Depressed dopamine activity in caudate and preliminary evidence of limbic involvement in adults with attention-deficit/hyperactivity disorder. Arch Gen Psychiatry 64(8):932-940

Wittchen HU, Zaudig M, Fydrich T (1997) Strukturiertes klinisches Interview für DSM-IV Achse I und II. Hogrefe, Göttingen

Wong AH, Macciardi F, Klempan T, Kawczynski W, Barr CL, Lakatoo $S$ et al (2003) Identification of candidate genes for psychosis in rat models, and possible association between schizophrenia and the 14-3-3eta gene. Mol Psychiatry 8:156166

Yildiz-Yesiloglu A, Ankerst DP (2006) Neurochemical alterations of the brain in bipolar disorder and their implications for pathophysiology: a systematic review of the in vivo proton magnetic resonance spectroscopy findings. Prog Neuropsychopharmacol Biol Psychiatry 30:969-995

Young CE, Arima K, Xie J, Hu L, Beach TG, Falkai P et al (1998) SNAP-25 deficit and hippocampal connectivity in schizophrenia. Cereb Cortex 8:261-268 